\title{
DEEECÇÃO SOROLÓGICA DE ANTI-HPV 16 E 18 E SUA ASSOCIAÇÄO COM OS ACHADOS DO PAPANICOLAOU EM ADOLESCENTES E MULHERES JOVENS
}

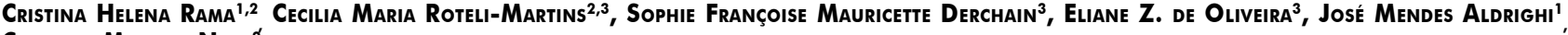 \\ Corintio Mariani Neto? \\ Trabalho realizado na Faculdade de Saúde Pública da Universidade de São Paulo', Hospital Leonor M. de Barros² e Universidade Estadual de \\ Campinas (UNICAMP) ${ }^{3}$, SP.
}

* Correspondência: Rua Pedro Cacunda, 344 apto 131, Jardim São Paulo, São Paulo, SP, Cep: $020-46090$

\begin{abstract}
RESUMO
OBjetivo. Verificar a taxa de anticorpos neutralizantes anti-HPV I6 e/ou 18, e a sua associação com os achados da citologia oncológica do colo uterino em adolescentes e mulheres jovens.

Métodos. Foram incluídas, neste estudo transversal, 54I mulheres de 15 a 25 anos de idade, saudáveis, sexualmente ativas, que apresentaram exame ginecológico normal, no período de setembro a novembro de 2000. Foi obtida uma amostra cervical para citologia em meio líquido e uma amostra de sangue para identificação dos anticorpos anti-HPV I6 e/ou 18, por meio do método ELISA. As amostras foram encaminhadas para um laboratório de referência na Bélgica.

Para análise estatística, foram estimadas a prevalência e a razão de prevalência (RP), com intervalo de confiança de $95 \%$.

Resultados. Entre as mulheres incluídas, I50 (27,7\%) apresentaram resultados positivos da sorologia sendo: 79 (14,6\%) por anticorpos anti-HPV 16, 35 (6,4\%) anti-HPV 18 e $36(6,6 \%)$ anti-HPV 16 e 18. Foram detectadas anormalidades citológicas em 107 casos (20,5\%), sendo 63 classificadas como atipias celulares de significado indeteminado (ASCUS), 41 casos suggestivos de lesões de baixo (LSIL) e três casos sugestivos de lesões de alto grau (HSIL). A prevalência de citologias anormais quando a sorologia foi positiva foi apenas I,75 vez a prevalência de citologias positivas observadas com sorologia negativa. Nesta amostra não houve evidência de associação entre os resultados anormais da citologia e a positividade da sorologia.
\end{abstract}

Conclusão. $O$ resultado deste estudo indica uma alta prevalência de sorologia positiva para o HPV 16 e 18 em mulheres jovens sadias sem relação com os achados anormais da colpocitologia.

UnIteRmos: Sorologia. Anticorpos anti-HPV. Colpocitologia. Neoplasia.

\section{INTRODUÇÃO}

A infecção do papilomavírus humano de alto risco (HPV) representa atualmente o fator de risco mais importante na gênese do carcinoma de colo uterino ${ }^{1,2,3}$. Estudos caso-controle indicam a presença do HPV associado ao câncer cervical com um risco relativo que varia ao redor de 50 a 150 para os chamados genótipos virais de alto risco, principalmente os mais prevalentes, 16 e 184,5.6. O tipo de HPV 16, de alto risco oncológico, foi considerado pela IARC (Internacional Agency for Research on Cancer) como definitivamente carcinogênico para a raça humana?.

Com uma prevalência de $15 \%$ a 40 \% na população geral, a infecção cervical por HPV, atualmente, representa a doença sexualmente transmissível (DST) isolada mais freqüente no mundo $0^{8,9}$. Apesar da alta prevalência, muitas infecções serão transitórias (60\%), o que é extremamente comum em jovens, apresentando duração média de 8 a 10 meses. Entretanto, as infecções persistentes são encontradas em $5 \%$ a $10 \%$ das mulheres com 35 anos ou mais, associando-se com aumento do risco de progressão neoplásica ${ }^{10,11}$.

Assim, a história natural do carcinoma do colo uterino pode ser dividida em três fases: a primeira quando está presente a infecção por
HPV, sem outras manifestações detectáveis; a segunda quando já estão presentes alterações morfológicas das células do epitélio do colo uterino, que caracterizam as lesões intra-epiteliais; e a terceira com a presença de lesão atravessando a membrana basal do epitélio, caracterizando o carcinoma invasor, fase esta irreversível e que se não tratada levará ao óbito ${ }^{12}$.

A introdução do Papanicolaou como teste de rastreamento há cerca de 50 anos resultou em espetacular redução dos índices de mortalidade por câncer cervical, ao redor de $50 \%$ a $70 \%{ }^{13,14}$. Entretanto, as taxas de mortalidade por câncer cervical permaneceram estáveis e até aumentaram em países com poucos recursos para implantação de programas de rastreamento organizados ${ }^{15}$.

Os métodos diagnósticos das lesões induzidas por HPV são morfológicos e incluem o exame clínico, a colposcopia, a citologia oncológica e a histologia. Já a identificaçãão da infecção por HPV propriamente dita inclui os métodos biológicos, como as hibridizações moleculares de ácidos nucléicos, tipo Southern Blot, captura de híbridos, hibridização in situ e reação em cadeia de polimerase $(P C R)^{16}$.

Anticorpos neutralizantes têm sido demonstrados no soro de mulheres infectadas por HPV. A maioria dos estudos tem examinado a prevalência destes anticorpos e os comparado com a presença de 
RAMA CH ET AL.

DNA viral por PCR, com neoplasia cervical ou com a presença de verrugas genitais. A interpretação dos resultados apresenta dificuldades porque ainda pouco se sabe sobre o desenvolvimento, a detecção e persistência dos anticorpos em relação à detecção do DNA-HPV ${ }^{17}$. Mais recentemente, o uso da detecção dos títulos sorológicos de anticorpos anti-HPV estão sendo estudados como indicadores de produção de anticorpos neutralizantes, nos ensaios clínicos que visam o desenvolvimento de vacinas profiláticas ${ }^{18}$.

Com relação ao uso da sorologia como possível marcador de infecção por HPV no colo uterino, existem dificuldades devido às reações cruzadas entre os diferentes tipos de HPV, que podem infectar diversas partes do organismo, assim como a fraca resposta das células imunocompetentes das camadas superficiais do epitélio, onde se dá a expressão viral do HPV ${ }^{18}$.

Vários esforços têm sido utilizados para desenvolver provas sorológicas mais sensíveis e específicas. Os primeiros testes baseavam-se em antígenos protéicos do virion denaturado, mais recentemente desenvolveram-se testes baseados em partículas virus like (VLP). Estas partículas derivam da expressão da maior proteína do capsídeo viral em células eucarióticas, podendo ser usadas para detectar anticorpos no soro de pacientes infectados ${ }^{19}$.

Um estudo de coorte acompanhou, por três anos, níveis de anticorpos para o capsídeo do HPV 16 em relação à detecção do HPV por PCR, colhido em colo e vagina de mulheres jovens. A média de tempo entre a primeira detecção do DNA do HPV e da soroconversão foi de 8,3 meses. Houve soroconversão de $93,7 \%$ já na primeira visita e de $67,1 \%$ dos casos com infecção incidente nas mulheres onde 0 DNA HPV I 6 foi detectado; enquanto que apenas $9,5 \%$ das mulheres com DNA HPV 16 negativas soroconverteram. A persistência do DNA HPV aumenta a probabilidade de persistência dos anticorpos e houve uma relação estatisticamente significativa da soropositividade com aumento do número de parceiros ${ }^{17}$.

A soropositividade do HPV 16 é fortemente associada com a detecção repetida do DNA HPV 16 na cérvix, sugerindo ser um marcador de infecção prolongada, associada com o desenvolvimento e persistência de lesões intra-epiteliais ${ }^{20}$.

A detecção de anticorpos séricos dos tipos de HPV de alto risco poderia ser um marcador das mulheres de risco para desenvolvimento da neoplasia cervical. Um ensaio sorológico seguro poderia se tornar um adjunto ao teste de Papanicolaou. Mas vários fatores devem ser levados em conta antes de considerarmos os testes sorológicos para o HPV como adjuvantes aos métodos correntes de controle de câncer do colo uterino ${ }^{17}$. Sabemos que a resposta humoral isoladamente não é suficiente para erradicar a infecção viral que depende também de uma resposta celular efetiva. A aquisição, a persistência e a progressão da infecção por HPV são determinadas pelo potencial viral (alto ou baixo risco), pelos mecanismos de controle intracelulares e também pela vigilância imune antiviral|8.

Assim, nos propusemos a estudar esta amostra de mulheres jovens, saudáveis, sem história de infecção por HPV, de baixo risco para as doenças sexualmente transmissíveis e com exame ginecológico normal, fazendo parte de um estudo epidemiológico prévio para um ensaio clínico com aplicação de vacinas profiláticas anti-HPV 16 e 18.

\section{Métodos}

Foram avaliadas 54I mulheres, de 15 a 25 anos, com vida sexualmente ativa, que espontaneamente procuraram o Serviço de Ginecologia do Hospital Leonor Mendes de Barros ou o Ambulatório de Ginecologia do Centro de Atenção Integral da Saúde da Mulher (CAISM) da Universidade Estadual de Campinas (UNICAMP) para exame de Papanicolaou. O termo de consentimento livre e esclarecido foi assinado pela mulher ou por seu responsável legal, no caso de menores. A seguir foi obtida uma amostra de sangue para sorologia, e foram submetidas a um exame ginecológico e colhida citologia oncológica em meio líquido.

Por ser parte de em estudo para recrutamento de voluntárias para um projeto de imunização de vacina candidata, profilática anti-HPV, os critérios de inclusão e exclusão visavam obter mulheres jovens, saudáveis, com baixo risco para doenças sexualmente transmissíveis. Foram incluídas mulheres sem problemas de saúde evidentes, pela história clínica e pelo exame físico direto, com não mais que quatro parceiros sexuais em todo o período de vida antes da participação no estudo, útero intacto e colo uterino de aspecto normal ao exame ginecológico.

Foram excluídas mulheres grávidas ou que estavam amamentando, as portadoras de corrimento vaginal anormal no momento de entrada no estudo, as que estavam sob tratamento ou esperando tratamento para condilomas externos e internos, as com lesões herpéticas cervicais ou vulvares extensas, as com história de citologia cervical anormal, as com tratamento de doença cervical por ablação (crioterapia ou ablação por laser) ou excisão (biópsia em cone com laser ou cirurgia de alta freqüência) e as com qualquer condição confirmada ou suspeita de imunossupressão ou imunodeficiência.

Uma amostra cervical foi colhida para citologia com escova cervical e espátula plástica. Ambas foram agitadas em um frasco de coleta em meio líquido de preservação/transporte (preserv Cyt) de modo a recuperar as células esfoliadas. O Thin Prep 2000 Processorfoi utilizado para transferir e fixar as células em lâminas de vidro. As lâminas foram classificadas de acordo com o sistema Bethesda ${ }^{21}$.

Foi coletada amostra de $10 \mathrm{ml}$ de sangue e a partir dela preparadas duas alíquotas de soro. Uma delas enviada para processamento em um laboratório na Bélgica (SBBio Lab ) e a outra armazenada em freezer a $-20^{\circ} \mathrm{C}$, para o caso de perda da outra amostra no transporte.

O teste utilizado foi desenvolvido e estandartizado pela Méd Immune sendo similar ao do National Cancer Institute. Utilizou-se um antígeno altamente purificado HPV L I virus like particles (tipos 16 e 18) produzido em células de insetos, com mais de 95\% de pureza, e controles positivos e negativos para cada ensaio ${ }^{22}$.

A quantificação de anticorpos anti-HPV 16 e HPV 18 VLPs (anti-VLP 16 e anti-VLP 18) foi realizada pelo método ELISA usando VLPS específicos como antígenos de cobertura. Os títulos ELISA são calculados e expressos em EU/mkl. O cut-off foi estabelecido com painel de soros de adolescentes virgens, com técnica descrita por Evans e colaboradores $^{19}$.

Todos os resultados foram para análise estatística, sendo estimadas a prevalência e a razão de prevalência (RP), com intervalo de confiança de $95 \%$.

Este trabalho foi aprovado pelos Comitês de Ética em Pesquisa do Hospital Leonor Mendes de Barros e da Universidade Estadual de Campinas. 
Tabela I - Distribuição dos resultados sorológicos anti-HPV 16 e 18

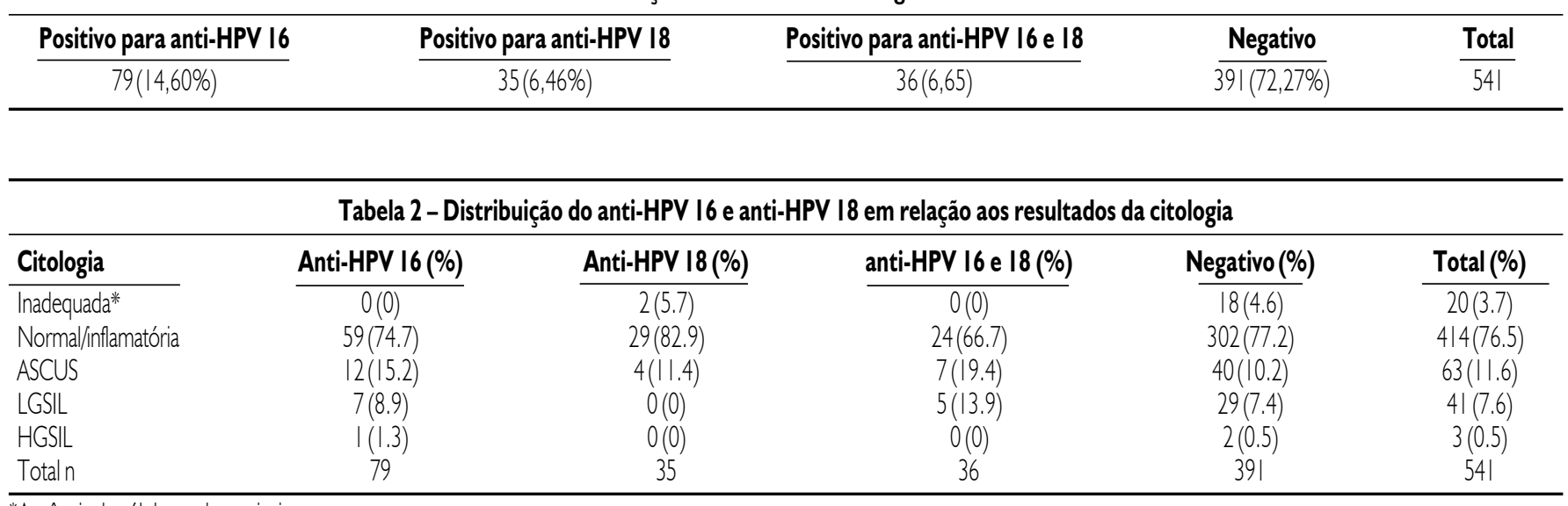

*Ausência de células endocervicais

Tabela 3 - Prevalência dos achados de sorologia em relação aos resultados anormais da citologia

\begin{tabular}{|c|c|c|c|c|}
\hline & & & & \\
\hline & Total & $n$ & $\%$ & RP (IC 95\%) \\
\hline Negativo & 373 & 71 & 19,0 & referência \\
\hline Anti-HPV I6 & 79 & 20 & 25,3 & $1,33(0,86-2,05)$ \\
\hline Anti-HPV I8 & 33 & 4 & $\mid 2,1$ & $0,64(0,24-1,63)$ \\
\hline Ambos & 36 & 12 & 33,3 & $1,75(1,05-2,91)$ \\
\hline
\end{tabular}

\section{Resultados}

Das 54 I mulheres examinadas, I 50 (27,72\%) apresentaram sorologia positiva para anticorpos anti-HPV 16 ou HPV 18 ou ambos. Com a seguinte distribuição: 79 (|4,60\%) anticorpos anti-HPV |6, 35 (6,46\%) anticorpos anti-HPV 18 e 36 (6,65\%) das mulheres apresentaram-se positivas para ambos (Tabela I).

Com relação à distribuição dos anticorpos e sua relação com os resultados dos esfregaços citológicos, verificamos que $25,3 \%$ das mulheres que eram positivas para anti-HPV 16 apresentavam citologia alterada. Esta porcentagem aumenta para 33,3\% quando encontramos positividade sorológica para os tipos de HPV 16 e 18 com uma RP de I,75 (Tabela 3 e Gráfico I). Para análise estatística dos resultados da citologia, foram excluídas 20 amostras com resultado inadequado por ausência de células endocervicais.

\section{Discussão}

Neste estudo, avaliou-se a sorologia específica anti-HPV I6/I8 e o resultado do Papanicolaou em mulheres jovens, participantes de um projeto de recrutamento, visando futura administração de vacina profilática contra HPV 16/18.

As mulheres deste estudo obedeceram a critérios de inclusão que não permitiam história prévia de infecção por HPV, assim como estabeleciam limites para o número de parceiros sexuais, que são fatores sabidamente relacionados ao aumento do risco da infecção" .

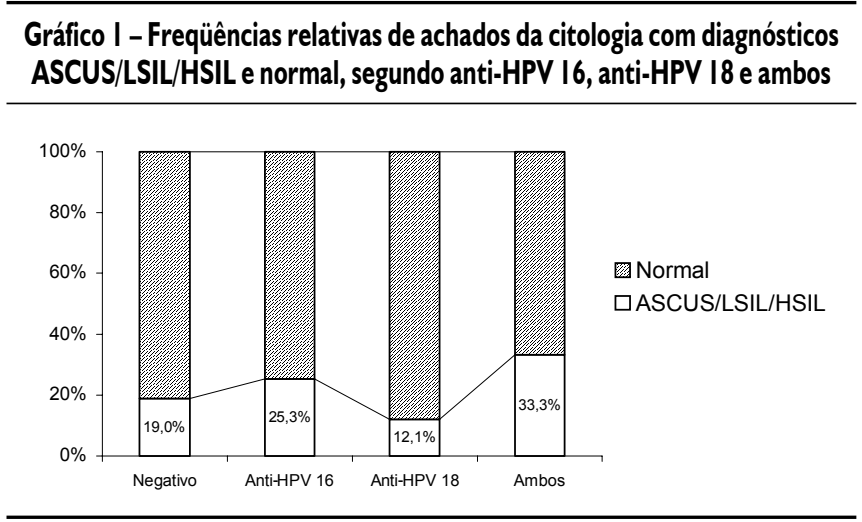

Em nosso estudo, detectamos $27,7 \%$ de resultados positivos para HPVI6/18, isolados ou associados. Esta alta prevalência de positividade, mesmo sendo em mulheres muito jovens e com baixo risco para doenças sexualmente transmissíveis, pode ser interpretada como resposta sorológica recente, uma vez que são mulheres que estão iniciando sua atividade sexual.

A infecção genital por HPV se inicia com o vírus penetrando na superfície do colo uterino através de lesões na zona de transformação do epitélio escamoso, induzindo uma resposta celular local e sistêmica. A resposta celular local vai refletir a capacidade de produção de anticorpos pelas células de 
RAMA CH ET AL.

Langerhans, como primeira linha de defesa. Já a resposta sorológica pode significar apenas a presença do vírus como infecção transitória ou recém-adquirida ${ }^{18}$.

Assim, detectamos anormalidades citológicas em aproximadamente $20 \%$ das 45 I citologias colhidas, sendo mais da metade (59\%) classificadas como atipias celulares de significado indeterminado (ASCUS) e $41 \%$ com lesões de baixo (LSIL) ou alto grau (HSIL).

Em relação à associação das alterações citológicas com a positividade da sorologia, verificamos que aproximadamente $70 \%$ das sorologias positivas apresentavam citologia normal. Isto pode ser explicado pela aquisição de uma infecção recente que ainda não se integrou ao genoma do hospedeiro, ou ainda por infecções em outras localizações que não a área genital (reações cruzadas).

As citologias anormais com sorologia positiva para o HPVI6 mostraram uma positividade em $25,3 \%$ dos casos, e essa positividade aumenta para 33,3\% quando achados ambos HPV. A prevalência de citologias positivas é 1,75 vez em relação à prevalência de citologias positivas observadas quando a sorologia é negativa. Estes resultados são concordantes com achados em outros trabalhos que relacionaram a detecção de anticorpos com a gravidade da lesão cervical na presença de anticorpos anti-HPV $16^{17,20}$.

Embora a prevalência da infecção por HPV seja maior em mulheres jovens quando comparada com mulheres com mais de 30 anos, muitas destas infecções irão regredir espontaneamente dentro de um período de 24 meses, sendo consideradas infecções transitórias sem lesões intra-epiteliais devido ao desenvolvimento de anticorpos neutralizantes ${ }^{17,18}$. Assim, a alta taxa de detecção de anticorpos em mulheres com baixo risco para doenças sexualmente transmissíveis sugere uma exposição às proteínas do HPV de alto risco para neoplasias cervicais, no início de sua atividade sexual.

Apesar do teste ser viável sob o ponto de vista econômico e ser considerado o único marcador sorológico confiável, ainda não consegue ser utilizado para diagnóstico devido à assincronia com a infecção e a sua regressão ${ }^{18}$.

Os resultados na literatura sugerem que a detecção dos anticorpos é associada com a persistência da replicação viral e que os títulos caem e desaparecem rapidamente nas infecções consideradas transitórias ${ }^{20}$. Entretanto, tem sido utilizada para monitorização de participantes voluntárias e em protocolos de imunização profilática ou terapêutica.

Verificamos que a sorologia não conseguiu detectar todas as alterações celulares demonstradas pela citologia nesta amostra. São necessários estudos de acompanhamento dos casos positivos, tanto para anticorpos quanto para alterações celulares, visando uma melhor compreensão do papel da sorologia na história natural da neoplasia cervical.

\section{Conclusão}

O resultado deste estudo indica uma alta prevalência de sorologia positiva para o HPV 16 e 18 em mulheres jovens sadias sem relação com os achados anormais da colpocitologia e poderá contribuir para avaliação do comportamento da infecção por HPV, especialmente em mulheres candidatas à vacina profilática para prevenção de lesões do colo uterino induzidas por HPV.

\section{Agradecimentos}

Os autores agradecem ao estatísco Edson Z. Martinez pelo auxílio na análise estatística.

\section{Conflito de interesse: não há.}

\section{SUMMARY}

Serological detection of ANTI hPV $16 / 18$ and ITS ASSOCIATION WITH PAP SMEAR IN ADOLESCENTS AND YOUNG WOMEN

OBJECTIVE. Verify the relation between HPV /6//8 antibodies and the association with cervical cytology findings in adolescents and youngwomen.

METHODS. A cross sectional study with 54 I healthy and sexually active women from 15 to 25 years of age was carried on from September to November 2000. At gynecological examination, a cervical sample on liquid-base for cytology-testing and a bblood sample for ELISA identification of HPV 16 and 18 antibodies were collected and sent to a reference laboratory in Belgium. Statistical analysis estimated the prevalence and prevalence ratio with a 95\% confidence interval.

RESULTS. Ofthese youngwomen, 150(27.7\%) were seropositive: 79 (14.6\%) to HPV 16 antibody; 35 (6.4\%) to HPV 18 antibody and 36 (6.6\%) to both HPV I6/I8 antibodies.

Cytological abnormalities were detected in 107 cases (20.5\%): 63 presented with atypical squamous cells of undetermined significance (ASCUS), 4 I were suggestive of low grade squamous intra-epithelial lesion (LGSIL) and 3 of high grade squamous intraepithelial lesion (HGSIL). Prevalence of abnormal cytology with a positive serology was only I.75 times that of prevalence of abnormal cytology with a negative serology. Detection of abnormal cytology was not correlated with positive serology.

CONCLUSION. Results of this study indicate a high prevalence of HPV 16 and 18 in young healthy women which showed no relation to the abnormal findings of cytology smears. [Rev Assoc Med Bras 2006; 52(I): 43-7]

KEY WORDs: Serology. Antibodies anti HPV. Colpocitology. Neoplasia.

\section{REFERÊNCIAS}

I. Walboomers JMM, lacobs MV, Mannos MM, Bosch XF, Kummer A, Shah $K V$, et al. Human papillomavirus, a necessary cause of invasive cervical cancer wordwide. J Pathol 1999; | 89: I2-9.

2. Bosch FX, Munhoz N, Manos MM, Sherman M, lansen Am, Peto J, et al. Prevalence of human papillomavirus in cervical cancer: a wordwide perspective.J Natl Cancer Inst 1995;87:796-802.

3. Schiffman MH, Bauer HM, Hoover RN, Glass AG, Cadell DM, Rush BB, et al. Epidemiologic evidence showing that Human Papillomavirus infection causes most cervical intraepithelial neoplasia. J Natl Cancer Inst 1993;85:958-64.

4. Bosh FX, Lorinez A, Munoz N, Meyer CJML, Shak KV. The casual relation between human papillomavirus and cervical cancer. J Clin Pathol 2002; 55: 244-65.

5. Rozendaal L, Walboomers JM, Van der Linden JC, Voorhort FJ, Kenemans P, Helmerhorst T], et al. PCR-based high-risk HPV test in cervical cancer secreening gives objective risk assessment of women with cytomorphologically normal cervical smear. Int J Cancer 1996;68:766-79. 
6. Syrjänen K, Mäntyjärvi R, Saarikoski S, Väyrynen M, Syrjänen S, Parkkinen $S$, et al. Factors associated with progression of cervical human papillomavirus (HPV) infections into carcinoma in situ during a long- term prospective follow-up. Br J Obstet Gynaecol 1988;95 I096-I02.

7. [IARC.] Internacional Agency for Research on cancer monograph on the evaluation of carcinogenic riscks to human. Human papillomaviruses, vol. 64 Lyon: 1995.

8. Swygart C. Human papillomavirus: disease and laboratory diagnosis. Br J Biomed Sci 1997;54:299-303.

9. Woodman CB, Collins S, Winter H, Bailey A, Ellis J, Prior P, et al. Natural history of cervical human papillomavirus infection young women: a longitudinal cohort study. Lancet 200 I;357(927 I): I 83 I -6.

10. Beutner KR, Tyring S. Human papillomavirus and human disease. Am J Med 1997; 102:9-15.

I I. Ho GYF, Bierman R, Beardsley L, Chang C), Burk RD. Natural history of cervicovaginal pappilomavirus infection in young women. $N$ Engl J Med 1998;338:423-8.

12. Zeferino LC, Amaral RG, Dufloth RM. HPV e a neoplasia do colo do útero Femina 2002;30:47I-5.

13. De Sanjose S, Santamaria M, Alonso de Ruiz P, Aristizabal N, Guerrero E, Castellsague $X$, et al. HPV types in woman with normal cervical cytology. IARC Sci Publ 1992; I 19:75-84.

14. Fahey MT, Irwing L, Macaskill P. Meta analysis of Pap test accuracy. Am J Epidemiol 1995; | 41:680-9.

15. Stoller $\mathrm{MH}$. Advances in cervical screening tecnology. Mod Pathol 2000; 13:275-84

16. Carvalho JJM, Oyakawa N. Papilomavírus humano. I Consenso Brasileiro de HPV. São Roque; 1999.
17. Carter J], Koutsky LA, Wipf GC, Christensen ND, Lee SK, Kuypers ], Kiviat N, Galloway. The natural history of human papillomavirus type 16 capsid antibodies among a cohort of university women. J Infect Dis 1996; 174:927-36

18. Coursaget P. Serology for human papillomavirus. Salud Publica Mex 2003;45:36I-6

19. Evans TG, Bonnez W, Rose RC, Koenig S, Demeter L, Suzich JÁ, et al. A phase I study of a recombinant viruslike particle vaccine against human papillomavirus type II in health adult volunteers. J Infect Dis 200। ; 183: | 485-93.

20. Wideroff L, Schiffman MH, Haderer P, Armstrong A, Geer CE, Manos MM. Seroreactivity to human papillomavirus type 16, I8, 3 I and 45 VLP in a case control study of cervical squamous intraephitelial lesions. J Infect Dis 1999; | 80: | 424-8.

21. The 1988 Bethesda system for reporting cervical/ vaginal cytologic diagnosis. Acta Cytol 1988, 567-7I.

22. Kinrbauer R, Hubbert NL, Wheeler CM, Becker TM, Lowy DR, Schiller JT. A virus like particle enzyme-linked immunosorbent assay detects serum antibodies in a majority of women infected with human papillomavirus type 16. J Natl Cancer Inst 1994;86:494-8.

Artigo recebido: 19/08/04 Aceito para publicação: 28/06/05 